\title{
Using of Waste Materials to Stabilize Expansive Clay for Airport Rigid Pavement
}

\author{
Mohamed S Ouf ${ }^{1}$, Abdelzaher Mostafa ${ }^{1}$, M. Ibrahim ${ }^{2}$ \\ 1Associate Prof. Civil Engineering, Faculty of Engineering, Helwan University, Egypt \\ 2Postgraduate Student, Civil Engineering, Faculty of Engineering, Helwan University, Egypt
}

\begin{abstract}
Rigid pavement rested on clayey soil may be adversely affected by the behavior of sub-grade soil. The clayey soil may swell or shrink which causes unexpected cracks in pavement and therefore needs greater thickness to sustain the expected loads. The objective of this study is to achieve an economic design of rigid pavement on expansive clay. Specimens of reinforced concrete slabs were tested on a bed of Egyptian soil and were loaded until failure. Firstly, a reinforced concrete slab supported on a well compacted natural soil was tested to sustain the expected traffic loads without any additives. Secondly, improve the sub-grade soil under the rigid pavement using ground granulated blast furnace slag, cement dust, and lime. Thirdly, improve the sub-grade soil under the rigid pavement using ground granulated blast furnace slag (GGBS), cement dust (CD), and lime (L) stabilizers. Fourthly, replace the expansive soil (ES) using sand layer Firstly, improve the in-situ materials by normal compaction methods and design for the modified properties to sustain the expected traffic loads without any additives. Secondly, improve the sub-grade soil under the rigid pavement using ground granulated blast furnace slag (GGBS), cement dust (CD), and lime (L). Thirdly, improve the sub-grade soil under the rigid pavement using ground granulated blast furnace slag (GGBS), cement dust (CD), and lime (L) stabilizers. Fourthly, replace the expansive soil (ES) using sand layer. The results of this study proved that the best alternative to obtain the best stress / strain ratio was using GGBS and lime (3:1 ratio) to stabilize the natural soil and the percentage of total binder was $6 \%$ by dry weight of soil.
\end{abstract}

Keywords: Airport, rigid pavement, expansive clay, waste materials, blast furnace slag

\section{Introduction}

The cost of any roads and airports project includes initial costs and subsequent maintenance costs. The initial costs include many items such as land, bridges and subways, drainage, pavement construction etc. Therefore, decreasing the cost of pavement construction is very beneficial. It is essential to take into consideration the conditions of the subgrade soil before designing the type and the thickness of the pavement (Bari 1995, Ouf 2001).

Airfields rigid pavement rested on clay soil may be adversely affected by the behavior of sub-grade soil. Expansive clays are those which suffer volume and behavior changes with changes of water content which results in the break-up of road pavements and damage to light structures. Replacement of such clays by other materials is generally expensive due to the high costs of excavation and disposal of unsuitable materials and the import and placing suitable fill. This is a particular problem in developing countries where construction costs are critical. The most appropriate method will usually be determined by economic considerations, for example it may be cheaper to stabilize a soil using relatively expensive additives rather than excavate and dispose of unsuitable materials and import and place suitable fill, as well as the properties of the subgrade (Ouf 2001). The volume change of some clayey soils due to change in their water content represent one of the most serious problems in the field of foundation engineering. Volume change and swelling pressures in clayey soils depend on clay type, pore volume, pore solution (including salt concentration) and particle-to-particle forces (Mowafy et al.1990). Volume change and swelling pressure are closely related and estimation of volume change of soil gives an indication of its swelling pressure and vice versa. In chemical soil stabilization processes, it has been established that new cementations materials are formed and alter the particle-to-particle forces through the cementations effects that these reaction products impart. Due to the formation of these cementations materials, the pore fluid and pore pressure will then be decreased, thus reducing the swelling pressure and the swelling potential and leading to volume stability (Kinuthia 1997).

Soil heave due to soil swelling is common in the field and causes tensile stresses in the upper parts of the structure. Alternatively, shrinkage may cause dishing, resulting in tensile stresses in the foundations, which can better resist such stresses (Ouf 2001, Kariuki and Meer 2004, and Xidakis 1979). Heave is mainly due to an increase in moisture content under the covered area not depending on the environmental conditions, (Eren and Filiz 2009).

There are many methods to control heave potential including control of compaction such as compaction at lower density and higher moisture content and chemical stabilization with lime and cement (Mowafy et al. 1990, Ouf 2001).

Researchers have considered the use of some by-product materials as alternative materials to cement and also to lime. The use of by-products has environmental and economic benefits. Ground granulated blast furnace slag (GGBS), has been suggested as a binder. It is mainly used, after being ground to fine GGBS, to produce blended cement. However, it has not been used as a soil stabilizer agent in Egypt although it has been used in the U.K and South Africa. GGBS on its own has only mild cementations properties and it is generally used in combination with Portland cement or hydrated lime (calcium hydroxide) which provides the necessary alkali activation (Higgins et al 1998, Oner and Akyuz 2007, 


\section{International Journal of Science and Research (IJSR) \\ ISSN (Online): 2319-7064 \\ Index Copernicus Value (2013): 6.14 | Impact Factor (2014): 5.611}

O'Rourke et al. 2009). The type of stabilization chosen in any project depends on both the properties of the soil involved and the nature of the project (Abdi 1992, Matter 2010, and Cuisinier etal. 2011).

Portland cement concrete is considered to be a relatively brittle material. When subjected to tensile stresses, nonreinforced concrete may crack and fail. More recently micro fibers, such as those used in traditional composite materials have been introduced into the concrete mixture to increase its toughness, or ability to resist crack growth. FRC is Portland cement concrete reinforced with more or less randomly distributed fibers. In FRC, thousands of small fibers are dispersed and distributed randomly in the concrete during mixing, and thus improve concrete properties in all directions. Fibers can improve the post peak ductility performance, pre-crack tensile strength, fatigue strength, and eliminate temperature and shrinkage cracks (Rongguo and Hong yin 2001, and Halasa et al. 2005).

The polymer chains are arranged randomly in no preferred direction during crystallization of the polymer. The real advantage of adding fibers is when fibers bridge these cracks and undergo pullout processes, such that the deformation can continue only with the further input of energy from the loading source.

Characteristics of rigid pavement under airplane loads can be improved using three possible alternatives. Firstly, improve the in-situ materials by normal compaction methods and design for the modified properties to sustain the expected traffic loads without any additives. Secondly, improve the mechanical properties of concrete using (FA), (SF) and (PPF) additives. Thirdly, improve the sub-grade soil under the rigid pavement using (GGBS), (CD), and (L) stabilizers. Fourthly, replace the expansive soil (ES) using sand layer.

\section{Research Objectives and Scope}

The main objectives of this research are to evaluate all possible alternatives mentioned above to use in the construction of rigid pavement. In addition, a comparison study in order to obtain the technically and economically optimum rigid pavement design will be carried out. To achieve the research objectives, twenty four slabs were prepared and tested. These specimens were grouped according to the different parameters that were considered in this study. These parameters are the concrete slab thickness, silica fume (SF), fly ash(FA) and polypropylene fiber with ordinary concrete (OC) to improve the mechanical properties of concrete. They also include the addition of GGBS, L and CD to expansive clay soil to obtain a stabilized base.

\section{Experimental Program}

The materials used in this research were chosen carefully and tested according to the Egyptian standards and universal specifications. A total of twenty four slabs were used in this investigation. These slabs were divided into two main groups, the first group (G1) contained twelve slabs of dimensions $100 \times 100 \times 6 \mathrm{~cm}$ slab while the second group (G2) contained another twelve slabs of dimensions $100 \times 100 \times 8 \mathrm{~cm}$. All slabs were reinforced with $8 \varnothing 6 \mathrm{~mm} / \mathrm{m}^{\prime}$ in both directions. Table (1) shows details of all slabs. A frame of $(300 \times 300 \times 100) \mathrm{cm}$ built from steel plates, bricks and mortar was used to simulate the actual field by preparing the soil and test the slabs, see figure (1). Also, photo (1) shows measuring strain in slab while Photo (2) shows the test of slabs. For more details refers to Al-Mashad 2001.

\subsection{Free Swelling Test}

Free swelling is defined as the increase in volume of the soil from a loose dry powder after it is poured into water, expressed as a percentage of the original volume. Free swelling test was carried out on all specimens that were subjected to unconfined compressive strength test (UCS) as described below. Free swelling was then calculated from the equation below (Head, 1992).

Free Swelling $=\frac{V-10}{10} \times 100$

\subsection{California Bearing Ratio Test Results}

The California bearing ratio (CBR) is a penetration test for evaluation of the mechanical strength of road sub and base courses. The CBR test is described in ASTM D1883-05 and AASHTO T193.CBR rating was developed for measuring the load-bearing capacity of soils used for building roads.

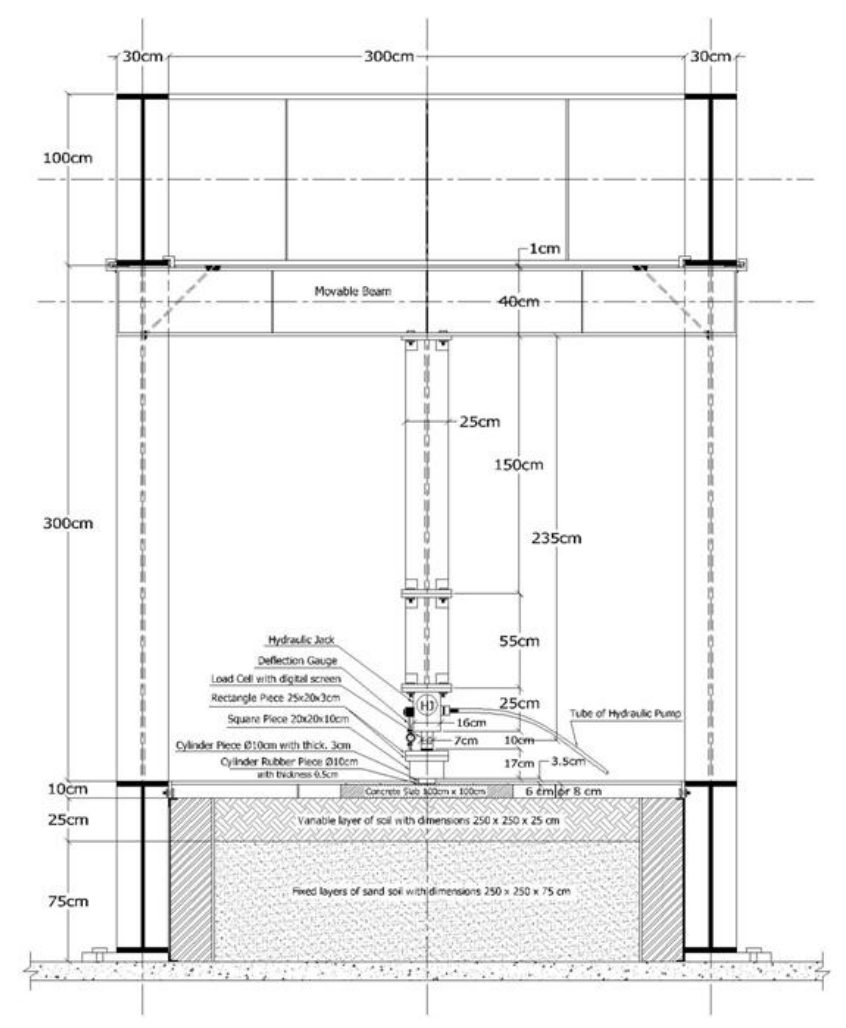




\section{International Journal of Science and Research (IJSR) \\ ISSN (Online): 2319-7064}

Index Copernicus Value (2013): 6.14 | Impact Factor (2014): 5.611

Table 1: Details of the tested slabs

\begin{tabular}{|c|c|c|c|c|}
\hline Group & $\begin{array}{l}\text { Case } \\
\text { Study }\end{array}$ & Symbol & Thickness & Description \\
\hline \multirow{14}{*}{ G1\&G2 } & \multirow{2}{*}{ 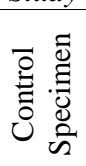 } & CS1 & $6 \mathrm{~cm}$ & \multirow[b]{2}{*}{ Ordinary R.C slab rested on ES without additives. } \\
\hline & & CS2 & $8 \mathrm{~cm}$ & \\
\hline & \multirow{4}{*}{ 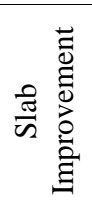 } & SI1 & $6 \mathrm{~cm}$ & \multirow{2}{*}{$\begin{array}{c}\text { Ordinary R.C slab with adding (30\%F.A+12\%S.F) of cement weight rested on ES with } \\
\text { additives. }\end{array}$} \\
\hline & & SI2 & $8 \mathrm{~cm}$ & \\
\hline & & SI3 & $6 \mathrm{~cm}$ & \multirow[b]{2}{*}{ Ordinary R.C slab with adding (2.0kg PPF/m³ of concrete) rested on ES without additives. } \\
\hline & & SI4 & $8 \mathrm{~cm}$ & \\
\hline & \multirow{8}{*}{ 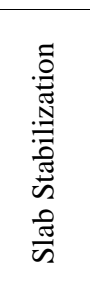 } & SS1 & $6 \mathrm{~cm}$ & \multirow{2}{*}{ Ordinary R.C slab rested on ES with adding 3\% (CD+L) by dry soil weight by (3:1 ratio). } \\
\hline & & D1 & $8 \mathrm{~cm}$ & \\
\hline & & SS3 & $6 \mathrm{~cm}$ & \multirow{2}{*}{ Ordinary R.C slab rested on ES with adding 6\% (CD+L) by dry soil weight by (3:1 ratio). } \\
\hline & & D2 & $8 \mathrm{~cm}$ & \\
\hline & & SS5 & $6 \mathrm{~cm}$ & \multirow{2}{*}{ Ordinary R.C slab rested on ES with adding 3\% (GGBS+L) by dry soil weight by (3:1 ratio). } \\
\hline & & G1 & $8 \mathrm{~cm}$ & \\
\hline & & SS7 & $6 \mathrm{~cm}$ & \multirow{2}{*}{ Ordinary R.C slab rested on ES with adding 6\% (GGBS+L) by dry soil weight by (3:1 ratio). } \\
\hline & & G2 & $8 \mathrm{~cm}$ & \\
\hline
\end{tabular}

Figure 1: Typical testing of rigid pavement

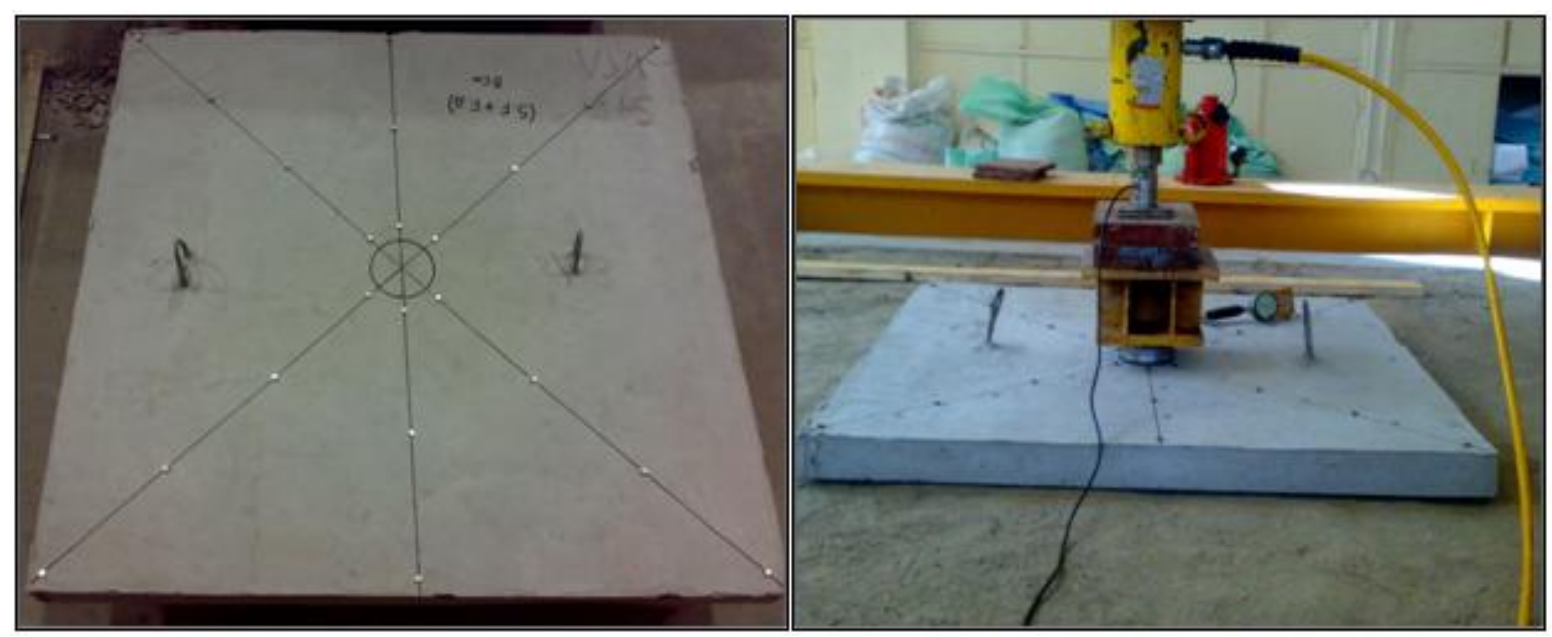

Photo 1: Measuring strain in slab

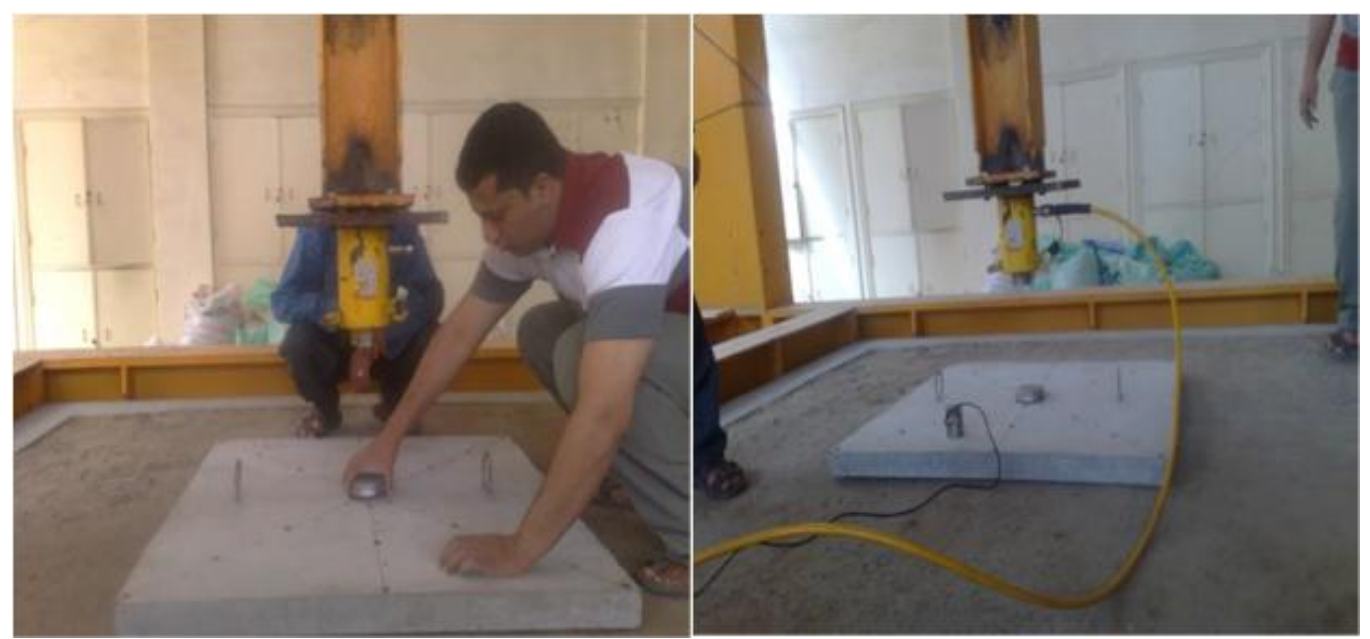

Photo 2: Test of slabs

Volume 5 Issue 1, January 2016

www.ijsr.net 


\section{International Journal of Science and Research (IJSR) ISSN (Online): 2319-7064}

Index Copernicus Value (2013): 6.14 | Impact Factor (2014): 5.611

\subsection{Unconfined Compressive Strength Test}

Unconfined Compressive Strength test (UCS) is a simple laboratory testing method to assess the mechanical properties of fine-grained soils. The UCS test is described in ASTM D2166 and AASHTO T208. To carry out these tests the specimens were taken out from the storage bags at the end of the curing periods, weighed to the nearest $0.01 \mathrm{~g}$ and the dimensions were measured. All specimens were tested in a universal test machine with a loading rate of 1.2 $\mathrm{mm} / \mathrm{min}$, so that the specimen fails in about 5 minutes, until failure. A minimum of three specimens of each mixture were tested. For details of mixing and testing refers to Al-Mashad 2001. The presented results are part of the obtained results and all obtained results will be presented in another paper.

\section{Results and Discussions}

\subsection{Free Swelling of Mixes}

The initial free swelling percentage (FSP) of the test soil was $110 \%$. The effects of adding stabilizers of different mixes on the (FSP) of the test soil are presented in figure (2). It can be seen that generally the FSP of the test soil decreased with an increase in the total stabilizer and with an increase in the curing period for the same combination. Increasing the total stabilizer caused a further decrease in the FSP for the same combination. For example, the FSP of the test soil decreased from $110 \%$ to $77 \%$ after 1 day for the mix D1, while the FSP further decreased to $50 \%$ for D2 combination. The least FSP obtained was $20 \%$ for the mix G2 after 28 days.

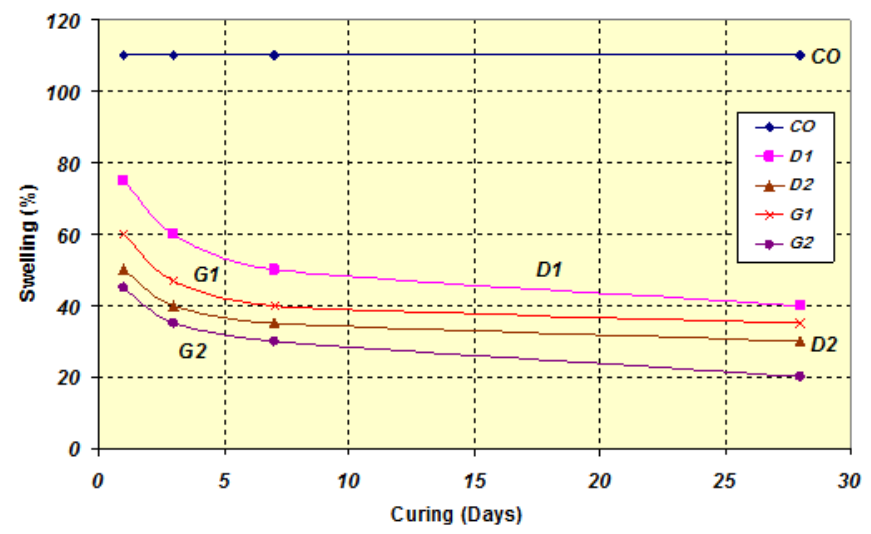

Figure 2: Effect of additives and curing period on free swelling

\subsection{CBR of Mixes}

CBR Test was carried out according to the procedures mentioned previously. Figure (3) shows the effect of additives on the CBR after curing periods of 1, 3, 7 and 28 days. It can be seen that generally the CBR of the test soil increased with an increase in the total stabilizer and with an increase in the curing period for the same combination. For example, the CBR of the test soil increased from 36\% for the control sample after 1 day to $61 \%$ after 28 days for mix D1 and the maximum CBR obtained was $83 \%$ for mix G2 after 28 days.

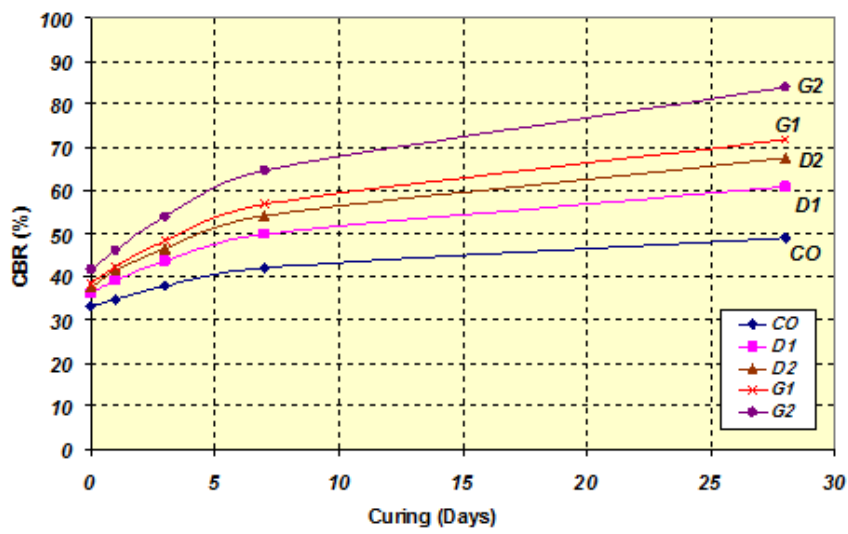

Figure 3: Effect of additives on CBR at curing periods 1, 3,7 and 28 days

\subsection{Unconfined Compressive Strength of Mixes}

The effects of adding stabilizers of different mixes on the UCS of the test soil are presented in Figure (4). It can be seen that generally the UCS of the test soil increased with an increase in the total stabilizer and with an increase in the curing period for the same combination. For example, the UCS increased up to $700 \mathrm{kN} / \mathrm{m}^{2}$ and $1500 \mathrm{kN} / \mathrm{m}^{2}$ for mix D1 and G2 respectively.

The swelling process of clay can be explained as enlargement of capillary films coating clay particles leading to a relaxation of effective compressive strength especially minerals with expanding characteristics such as montmorillonite (Mielenez and King, 1955 and Stucki, 2006). Abdi (1992) demonstrated that the average thickness of the water layer around each clay platelet increases linearly with an increase in moisture content, which means that expansion has a linear relationship with moisture and the process is reversible. The reactions of the binder with clay must, therefore, modify the clay particle surfaces in such a way that the water absorption and swelling capacity is reduced or produce reaction products from the clay which are not moisture content sensitive. The observation of the results showed that the swelling was significantly reduced to $18 \%$ from $26 \%$ which mean that any of the above mentioned mixtures would be useful to be used as stabilized mixture. The CD and L showed a better performance using $6 \%$ instead of $3 \%$ and adding the (GGBS+L) using 3\% showed reduced swelling 31 to $18 \%$ for the same percentages respectively.

Measuring the stabilizers effect using the UCS showed that using CD and L enhanced the UCS from $160 \%$ to $180 \%$ while GGBS activated by lime showed better performance (more than 300\%). The increase in the UCS with an increase in the additives content probably results from the reaction of the GGBS activated by lime with the clay portion of the test soil and the formation of new cementations materials. Many investigators have observed that high curing temperatures accelerate the reaction and result in higher early strength gain (Wild et al, 1987 and others). The rate of formation of cementations materials is the main reason for the strength increase at high temperatures, but the strength of the test soil also increases with an increase in the curing period due to development 


\section{International Journal of Science and Research (IJSR) ISSN (Online): 2319-7064}

Index Copernicus Value (2013): 6.14 | Impact Factor (2014): 5.611

in the crystallinity and percentage of the cementations materials. Wild et al., (1998) observed an increase in strength with an increase in lime/GGBS ratio up to a peak value and then a gradual decrease with an increase in lime/GGBS ratio. This peak probably depends upon soil type, clay content, and curing conditions and curing periods. Previous research (Kinuthia, 1997) on soil stabilization and pozzolanic reactions showed that the type, form, amount and characteristics of the reaction products control the physical, chemical and mechanical properties of the bulk material after stabilization.

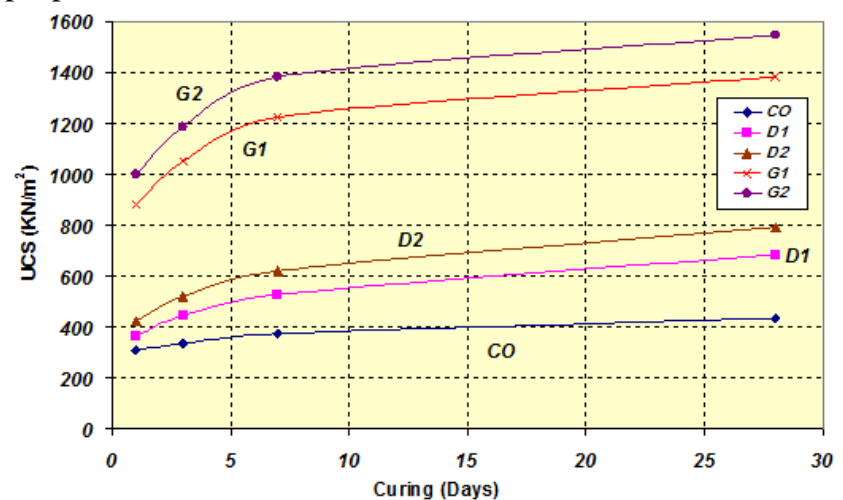

Figure 4: Effect of additives on UCS at curing periods 1, 3, 7 and 28 days

Table 2 shows the relationship between the percentage of ultimate load and the percentage of deflection at failure, while Figure 5 shows the relationship between the ultimate load and the maximum deflection for the different slabs. It can be observed that generally the failure load increases while the percentage of deflection decreases with an increase in binder content and with an increase in slab thickness for the same additives percentages. Also, it was observed that the best alternative is using 6\% (GGBS $+\mathrm{L}$ ) in soil stabilization of the top $25 \mathrm{~cm}$ of the subgrade soil. Using this combination obtains the maximum load causing failure and reduces the deflection

Table 2: Effect of soil stabilizer on ultimate load and deflection

\begin{tabular}{|c|c|c|c|c|}
\hline & \multicolumn{2}{|c|}{$8 \mathrm{~cm}$ slabs } & \multicolumn{2}{|c|}{$6 \mathrm{~cm}$ slabs } \\
\hline & $\begin{array}{l}\text { \% of ultimate } \\
\text { load at failure }\end{array}$ & $\%$ of deflection at failure & $\begin{array}{l}\% \text { of ultimate } \\
\text { load at failure }\end{array}$ & $\%$ of deflection at failure \\
\hline Control & 100.0 & 100.0 & 100.0 & 100.0 \\
\hline $3 \% C D+L$ & 147.0 & 68.1 & 138.2 & 72.8 \\
\hline $6 \% C D+L$ & 162.1 & 62.2 & 150.0 & 66.7 \\
\hline $3 \%$ GGBS $+\mathrm{L}$ & 181.8 & 55.0 & 160.0 & 62.5 \\
\hline $6 \% \mathrm{GGBS}+\mathrm{L}$ & 204.5 & 48.9 & 186.4 & 53.6 \\
\hline Sand & 115.2 & 86.8 & 111.8 & 89.4 \\
\hline
\end{tabular}

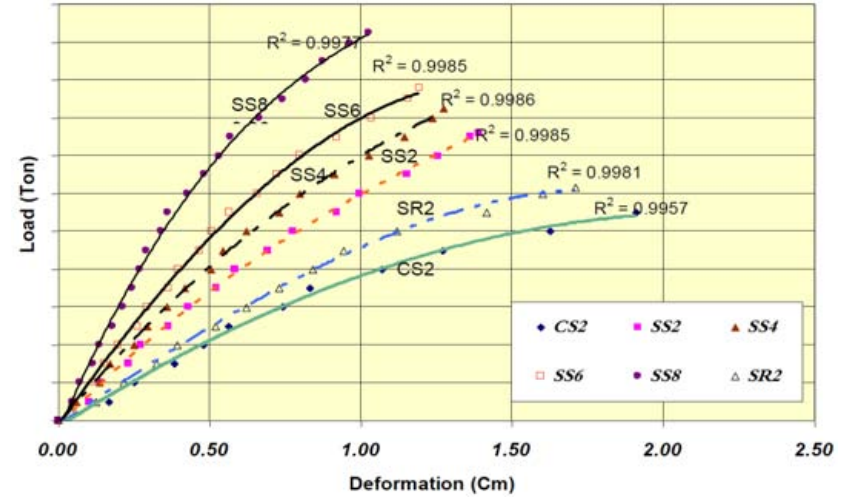

Figure 5: Effect of all admixtures on behavior of rigid pavement for $8 \mathrm{~cm}$ slab thickness

\section{Conclusions}

From the previous study the following could be concluded.

1. The FSP dramatically decreased with an increase in the binder content and curing period and the best alternative is using 6\% (GGBS $+\mathrm{L})$.

2. The CBR increased with an increase in the binder content and curing period and the best alternative is also 6\% (GGBS +L).

3. The UCS increased with an increase in the binder content and curing period and curing period and the best alternative is using $6 \%$ (GGBS $+\mathrm{L}$ ).

4. The failure load increases while the percentage of deflection decreases with an increase in binder content and with an increase in slab thickness for the same additives percentages. Also, the best alternative is using $6 \%$ (GGBS $+\mathrm{L}$ ) in soil stabilization of the top $25 \mathrm{~cm}$ of the subgrade soil. Using this combination obtains the maximum load causing failure and reduces the deflection.

5. The $8 \mathrm{~cm}$ thickness slab showed less deflection and more capability to resist loads when comparing with the same base and subbase conditions.

\section{References}

[1] Abdi, M R (1992),"Effect of Calcium Sulphate on Lime-Stabilized Kaolinite", Ph.D Thesis, Department of Civil and Building, The Polytechnic of Wales, Pontyprid, Mid Glamorgan, U. K.

[2] A.F. Halasa, Jean Marie Massie and R.J. Ceresa (2005), "The Chemical Modification of Polymers Science and Technology of Rubber", (Third Edition), Pages 497-528.

[3] Brian O'Rourke, Ciaran McNally and Mark G. Richardson (2009), "Development of calcium sulfateGGBS-Portland cement binders", Original Research Article Construction and Building Materials, Volume 23, Issue 1, Pages 340-346.

[4] Higgins, D.D, Kinuthia, J.M, and Wild, S. (1998), "Soil Stabilization Using Lime-Activated GGBS", Proceedings of the 6th Int. Conference, Fly Ash, Silica fume, Slag, and Natural Pozzolans in Concrete, Bangkok, Thailand, Vol. 2, pp. 1057-1074.

[5] Head K.H (1992), "Manual of Soil Laboratory Testing”, Volume 1: Soil Classification and Compaction Tests, London.

[6] J.W. Stucki, (2006), "Chapter 8 Properties and Behaviour of Iron in Clay Minerals, Review Article Developments in Clay Science", Volume 1, Pages 423-475.

[7] Kinuthia, J.M (1997), "Property Changes and Mechanism in Lime-Stabilized Kaolinite in the Presence of Metal Sulphate", Ph.D thesis, School of the Built Environment, University of Glamorgan, U. K.

[8] Olivier Cuisinier, Tangi Le Borgne, Dimitri Deneele, Farimah Masrouri (2011), "Quantification of the effects of nitrates, phosphates and chlorides on soil stabilization with lime and cement" Research Article Engineering Geology, Volume 117, Issues 3-4, 2, Pages 229-235. 


\section{International Journal of Science and Research (IJSR) \\ ISSN (Online): 2319-7064}

Index Copernicus Value (2013): 6.14 | Impact Factor (2014): 5.611

[9] Ouf, M.S.A (2001), "Stabilisation of Clay Subgrade Soils Using Ground Granulated Blastfurnace Slag", Ph.D. Thesis, School of Civil Engineering, University of Leeds, U.K.

[10] Patrick Chege Kariuki, and Freek van der Meer (2004), “A unified swelling potential index for expansive soils" Journal of Engineering Geology, Volume 72, Issues 1-2, Pages 1-8.

[11] Ş. Eren and M. Filiz (2009), "Comparing the conventional soil stabilization methods to the consolid system used as an alternative admixture matter in Isparta Darıdere" material Review Article Construction and Building Materials, Volume 23, Issue 7, Pages 2473-2480.

[12] Al-Moataz Bellah Ibrahim Abdel Salam El-Mashad (2011), "Optimization Study for Rigid Pavement Design at Airfields" M.Sc. Thesis, Faculty of Engineering at Mattaria Helwan, University 